\title{
Spontaneous fistulization of a liver abscess into the stomach
}

We present the case of a patient with pyogenic liver abscess that underwent spontaneous fistulization into the stomach.

A 69-year-old woman was admitted with acute renal failure due to urinary tract infection and sepsis. She had a history of diabetes mellitus, hypertension, and atrial fibrillation. During her stay in hospital, the patient developed iron deficiency anemia and underwent upper endoscopy, which showed a large ulcerated lesion on the anterior surface of the distal gastric body and lesser curvature, associated with a fistulous tract of pyogenic origin (๑ Video 1).

Abdominal computed tomography showed a 5-cm abscess in segment II of the left hepatic lobe, in continuity with the lesion in the gastric lumen ( Video 1 ). The patient was managed with bowel rest and was administered broad-spectrum antibiotics. There was gradual clinical improvement, and 3 months later a repeat upper endoscopy showed a 20-mm gastric ulcer on the distal gastric body, with no

\section{Video 1}

Upper endoscopy of the anterior aspect of the distal gastric body showing a large ulcerated lesion with a fistulous tract of pyogenic origin. On abdominal computed tomography, segment II of the left hepatic lobe had a $5-\mathrm{cm}$ abscess that was continuous with the lesion in the gastric lumen. evidence of the fistulous tract. Four months later there were no symptoms and the patient was discharged.

Pyogenic liver abscess is associated with an incidence of 22-446/100000 admissions per year $[1,2]$. Predisposing risk factors are diabetes mellitus, previous biliary surgery, and liver transplantation. The main etiology is cryptogenic, followed by biliary and inflammatory bowel disease [3]. The two most common causative organisms are Escherichia coli and Klebsiella pneumoniae $[1,2]$. The presentation often is insidious, particularly in elderly patients, and is characterized by malaise, low-grade fever, weight loss, and dull abdominal pain. A pyogenic liver abscess is usually solitary and occurs in the right liver lobe $[1,4]$. Ultrasonography and computed tomography are the initial imaging modalities of choice [1], and treatment includes parenteral antibiotics and percutaneous drainage $[1,2,5]$. In the present patient, drainage was postponed because of the initial benefit of the antibiotic treatment. However, during this period there was spontaneous fistulization into the stomach, which explains the clinical improvement. Our experience reinforces the importance of early drainage to avoid spontaneous rupture of the intraperitoneal abscess.

Endoscopy_UCTN_Code_CCL_1AB_2AD_3AF
S. Leite, A. P. Silva, J. Pinto, M. Afonso, R. Veloso, J. Carvalho, J. Fraga

Department of Gastroenterology and

Hepatology, Centro Hospitalar Vila Nova

Gaia/Espinho, Vila Nova de Gaia, Portugal

\section{References}

1 Seeto RK, Rockey DC. Pyogenic liver abscess: changes in etiology, management and outcome. Medicine 1996; 75: 99-113

2 Chan KS, Chen CM, Cheng KC et al. Pyogenic liver abscess: a retrospective analysis of 107 patients during a 3-year period. Jpn J Infect Dis 2005; 58 : $366-368$

3 Bahloul M, Chaari A, Bouaziz-Khlaf $N$ et al. Multiple pyogenic abscess. World J Gastroenterol 2006; 12: $2962-2963$

4 Giorgio A, de Stephano G, di Sarno A et al. Percutaneous needle aspiration of multiple pyogenic abscess of the liver: 13-year single-center experience. AJR Am J Roentgenol 2006; 187: 1585 - 1590

5 Barakate MS, Stephen MS, Waugh RC et al. Pyogenic liver abscess: a review of 10 years' experience in management. Aust N Z Surg 1999; 69: 205-209

\section{Bibliography}

DOI $10.1055 / \mathrm{s}-0029-1215205$

Endoscopy 2009; 41: E260

(c) Georg Thieme Verlag KG Stuttgart · New York . ISSN 0013-726X

\section{Corresponding author}

\section{S. C. B. A. Leite}

Department of Gastroenterology and Hepatology Centro Hospitalar Vila Nova Gaia/Espinho

Rua Conceição Fernandes s/n

4434-502 Vila Nova de Gaia

Portugal

Fax: +351-227830209

soniaclaraleite@gmail.com 